\title{
The Effect of CAP Policy Incentives for the Environmental and Economic Performance of Cereal Farms in South-Central Bulgaria
}

\author{
Mariya TOPCHIEVA*
}

Department of Environmental and Natural Resources Economics, University of National and World Economy,Osmi Dekemvri St., 1700 Sofia, Bulgaria

* corresponding author: maria_topchieva@abv.bg.

Bulletin UASVM series Agriculture 77(1) / 2020

Print ISSN 1843-5246; Electronic ISSN 1843-5386

DOI:10.15835/buasvmcn-agr: 2019.0025

\begin{abstract}
This paper aims to assess the effects of three mechanisms of the Common Agricultural Policy incentivizing environmentally friendly farming practices, on a model cereal farm's environmental and economic performance. Based on linear goal programming method and input data on the farm's size, production system, crop yield and gross margin per crop, the model optimizes the farm's production structure. The results indicate that the availability of support is essential for the economic results of cereal farms in South-Central Bulgaria. Generally, higher gross margin corresponds to higher greenhouse gas emissions and vice versa. Nevertheless, the addition of policy support decreases the degree of this dependency by improving the profitability of some less GHG-intensive crops. This allows farmers to consider more environmentally-friendly crops and production practices without having to cut profits. An optimal balance between farms' environmental and economic performance is crucial in order for agriculture to continue to support vital ecosystem services.
\end{abstract}

Keywords: Common Agricultural Policy, cereal farm, greenhouse gas emissions, multi-criteria optimization

\section{INTRODUCTION}

The agricultural production is essential for the health, prosperity and development of the human population. The sector provides food, clothing, feed and other products of primary importance. Furthermore, agriculture is a provider, but also a recipient of vital ecosystem services, such as carbon sequestration and biodiversity conservation among others (Swinton et al., 2007). However, the rapid growth and development of the sector in response to the growing population, has brought some serious negative environmental impacts. Nowadays the sector is the world's second largest emitter of greenhouse gas emissions and causes significant water pollution, soil degradation and biodiversity loss (Allen et al., 2014; Leip et al., 2017). A lot of research efforts have been invested in the recent years in the search for more environmentally friendly ways for agricultural production, assessing farms from different sectors, production systems and practices on the basis of multiple environmental and economic criteria (Bachev et al., 2017; Meier et al., 2015; Nemecek et al., 2015; Audsley, and Wilkinson, 2014).

In response to the sector's burden on the environment, the Common Agricultural Policy of the European Union (CAP) has been providing farmers with economic incentives for following environmentally sustainable farming practices since 1992. The CAP's environmental mechanisms have been evolving ever since and currently include the Pillar II organic farming compensatory payments (OF), the Green direct payments under Pillar I (CAP "Greening"), as well as the cross 
compliance obligatory rules, accompanying all Pillar I support schemes. The advisability and effectiveness of these measures, however, have been subject to discussion (Gocht et al., 2016; Pe'er et al., 2017; Concepción et al., 2020; Trapp, and Lakner, 2018).

This paper aims to assess the effects of the three CAP mechanisms supporting environmental measures, namely: the Single Area Payment Scheme (SAPS), the Green direct payments and the organic farming compensatory payments, on a model cereal farm's environmental and economic performance.The model optimizes the production structure of the farm, which includes some of the most common cereal crops and production systems in Bulgaria. The optimization is performed under a combination of environmental and economic goals, allowing to compare the trade-offs between the most environmentally friendly, the most profitable, as well as the optimal environmentaleconomic crop combinations. The three scenarios consider different economic reality: with or without policy support. This allows to assess the effect of the different policy support mechanisms on the farm's production structure and its related environmental and economic performance.

\section{MATERIALS AND METHODS}

The research method is linear goal programming with single/multi-criteria optimization.It is aimed at optimizing the production structure of a model cereal farm under economic and environmental goals. Linear goal programming has been used for the optimal allocation of resources in agriculture for decades (Shmelev et al., 2012). The challenges related to agricultural pollution and the agricultural-environmental linkages led to a new direction of the application of the classical crop simulation models, allowing for some of the negative environmental externalities to be included (Zekri and Boughanmi, 2007). The model developed for this research is based upon the linear goal programming method as described by Nikolov et al. (1994), to which an environmental dimension of crop production has been added with the support of LCA data. For the needs of the model, the territory of the South-Central region in Bulgaria (NUTS II) used for cereal crop production, is considered as one farm unit. The crop profile is based on data on the specialized cereal farms in the region (Ministry of Agriculture and Food,
2016). Therefore, the model contains 6 major crops: wheat, barley, maize, rapeseed, sunflower, alfalfa as nitrogen-fixing crop, and fallow land. All crops are included under two alternative production systems: conventional and organic. The variables of the model stand for the area referring to each crop in each of the two production systems.

In mathematical terms, the goal programming model is expressed as:

$$
\text { MAX F }=d^{+}+d^{-}(1)
$$

with target consraints: $A^{*} X-d^{+}+d^{-}=M(2)$

and resource constraints: $B^{*} X \geq$ or $\leq b(3) ; X \geq 0$; $d^{+} \geq 0 ; d^{-} \geq 0$.

where:

F represents the goal function,

$d^{-}-$vector $(m * 1)$ of negative deviations from achieving goal " $\mathrm{m}$ ";

$\mathrm{d}^{+}-$vector $(\mathrm{m} * 1)$ of positive deviations from achieving goal " $\mathrm{m}$ ";

A - matrix $\left(m^{*} n\right)$ of coefficients of the target constraints;

$X$ - vector $(n * 1)$ of variables in the model;

$M$ - vector $\left(m^{*} 1\right)$ of goals that have to be achieved;

$B$ - matrix $\left(p^{*} 1\right)$ of coefficients of the resource constraints;

$b$ - vector $(p * 1)$ of the resources of the resource constraints.

In order to examine the role of policy incentives for the optimization of the farm's environmental and economic performance, the optimization is conducted under three scenarios:

(1) without any support;

(2) with direct payments under the CAP Pillar I (SAPS and the CAP "Greening");

(3) with CAP Pillar I direct payments (SAPS and CAP "Greening") and CAP Pillar II compensatory payments (OF).

All optimization scenarios are conducted under three independent goals:

i. best environmental performance (single criteria optimization with goal to minimize the farm's emissions of greenhouse gases (GHG)). Agriculture is simultaneously contributing to climate change but also severely affected by it. The GHG emission intensity per crop and production system based on LCA data allows 
the model to simulate and minimize this contribution;

ii. best economic performance (single criteria optimization with goal to maximize the farm's gross margin). Despite the sector's specificities, profits are the main goal in business, as they secure development and continuance of operation;

iii. optimal environmental-economic performance (multi-criteria optimization with the environmental and economic goals simultaneously). An optimal balance between farms' environmental and economic performance is crucial in order for agriculture to continue to support vital ecosystem services.

Two target constraints are used for the optimizations. The target constraint for the farm's environmental performance equals $1084525204 \mathrm{~kg}$ $\mathrm{CO}_{2}$-eq and presents the emissions of greenhouse gases of the South-Central region in Bulgaria by keeping the recommended crop diversification for both conventional and organic arable land in the region (National Statistical Institute, 2018; Ministry of Agriculture and Food, 2013; Wernet et al., 2017). The target constraint for the farm's economic performance equals 133424160 Bulgarian leva (BGN) and is calculated by multiplying the land used for cereal farming in the region by an average gross margin of 40,8 BGN per dka (amount without subsidies) (National Statistical Institute, 2018; Ministry of Agriculture and Food, 2013).

The landuse constraint of the model equals the arable land used for production of the aforementioned crops in the South-Central region in Bulgaria (3 $300000 \mathrm{dka}$ ) (National Statistical Institute, 2018). The model involves crop diversification constraints for all crops and land uses $(25 \% \leq$ wheat $\leq 40 \% ; 5 \% \leq$ barley $\leq 15 \%$; $5 \% \leq$ maize $\leq 40 \% ; 0 \% \leq$ rapeseed $\leq 20 \% ; 0 \% \leq$ sunflower $\leq 25 \% ; 0 \% \leq$ alfalfa $\leq 25 \% ; 0 \% \leq$ fallow land $\leq 15 \%$ ), included in all scenarios (Ministry of Agriculture and Food, 2013; National Service for Plant Protection, 2008).

The requirements of the CAP "Greening" on crop diversification (no crop shall exceed $75 \%$ of the land) and ecological focus areas (EFA $\geq 5 \%$ of the land) are included in Scenarios (2) and (3) (Ministry of Agriculture, Food and Forestry, 2018). Scenario (3) includes a requirement for the organic area to exceed $8 \%$ in accordance with the national target set in the National Action Plan on
Development of the Organic Farming in Bulgaria by 2027 (Ministry of Agriculture, Food and Forestry, 2019).

The economic coefficients in the model present data on the gross margins for the different crops and production systems (Ministry of Agriculture and Food, 2013), as well as rates for the direct payments under the SAPS and CAP "Greening" and the rate for organic farming compensatory payments (Tab. 1). The rates for subsidies and compensatory payments refer to year 2015 for Bulgaria: 83,80 euro/ha under the SAPS (Ordinance № RD 09-341 of 03.06.2016 of the Minister of Agriculture and Food); 65,04 euro/ ha under the CAP "Greening" (Ordinance № RD 09-240 of 26.04.2016 of the Minister of Agriculture and Food); 168 euro/ha organic farming compensatory payment (Ordinance № 4 of 24.02.2015).

The environmental coefficients in the model present the generated amount of GHG emissionsfor the different crops and production systems (Tab. 1). They have been secured through the ecoinvent database v. 3.4, LCIA model ReCiPe Midpoint (H) (Wernet et al., 2017) and have been adapted with the yields per crop and production system (average yields at NUTS II level for the period 2012-2016) (National Statistical Institute, 2018).

The optimizations have been performed through LINGO v.18.0 optimization software of LINDO Systems.

\section{RESULTS AND DISCUSSIONS}

The results for the environmental and economic performance of the model farm in the different scenarios are presented in Tab. 2. Best environmental results for the model farm are achieved under the Environmental goal in Scenario 2 and Scenario 3, namely: $245822000 \mathrm{~kg}$ CO2-eq (equivalent of $22,67 \%$ of the environmental target constraint) (Figure 1). In terms of production structure, the solution does not vary in the different scenarios, and involves: organic wheat (40\%), organic barley (15\%), organic maize $(5 \%)$, alfalfa $(25 \%)$ and fallow land (15\%). Organic production system is preferred and wheat, barley and alfalfa are selected in their highest percent allowed, due to their lower intensity of GHG emissions per dka. Sunflower and rapeseed are not included in the producton structure, while maize is included in the lowest percent allowed, organically produced. 
Table. 1. Environmental and economic coefficients applied in the model

\begin{tabular}{|c|c|c|c|c|}
\hline \multirow[b]{2}{*}{ Crops: } & \multirow{2}{*}{$\begin{array}{c}\text { GHG emissions, } \\
\text { kg CO} \mathrm{C}_{2} \text {-eq per dka } \\
\text { In all scenarios }\end{array}$} & \multicolumn{3}{|c|}{$\begin{array}{l}\text { Gross margin, } \\
\text { BGN per dka }\end{array}$} \\
\hline & & $\begin{array}{c}\text { Scenario 1: } \\
\text { No subsidies }\end{array}$ & $\begin{array}{l}\text { Scenario 2: } \\
\text { SAPS and CAP } \\
\text { "Greening" }\end{array}$ & $\begin{array}{l}\text { Scenario 3: } \\
\text { SAPS, CAP } \\
\text { “Greening”, OF }\end{array}$ \\
\hline Conventional wheat & 262,45 & 54,00 & 83,11 & 83,11 \\
\hline Organic wheat & 96,41 & 30,00 & 59,11 & 91,97 \\
\hline Conventional barley & 276,97 & 49,00 & 78,11 & 78,11 \\
\hline Organic barley & 49,38 & 7,20 & 36,31 & 69,17 \\
\hline Conventional maize & 607,12 & 77,50 & 106,61 & 106,61 \\
\hline Organic maize & 136,75 & 32,90 & 62,01 & 94,87 \\
\hline Conventional rapeseed & 230,77 & 68,00 & 97,11 & 97,11 \\
\hline Organic rapeseed & 159,04 & 25,55 & 54,66 & 87,52 \\
\hline Conventional sunflower & 231,90 & 64,00 & 93,11 & 93,11 \\
\hline Organic sunflower & 154,73 & 24,04 & 53,15 & 86,01 \\
\hline Conventional alfalfa & 84,50 & 54,84 & 83,95 & 83,95 \\
\hline Organic alfalfa & 79,67 & 20,06 & 49,71 & 82,57 \\
\hline Fallow land & 11,77 & 0,00 & 29,11 & 29,11 \\
\hline
\end{tabular}

Source: ecoinvent database (Wernet et al., 2017); Ministry of Agriculture and Food (2013); Ordinance № 4 of 24.02.2015; Ordinance № RD 09-240 of 26.04.2016 of the Minister of Agriculture and Food; Ordinance № RD 09-341 of 03.06.2016 of the Minister of Agriculture and Food.

Although the GHG emissions under the Environmental goal in all scenarios are relatively constant, their corresponding gross margin values are subject to significant increase (nearly 290\%) (Figure 2 ). On the other side is the highest level of GHG emissions achieved. It is observed in Scenario 2 under the Economic goal of the model, which generated more than 4 times more GHG emissions. The corresponding production structure of the farm involves: conventional wheat $(24,79 \%)$, conventional barley (5\%), conventional maize (40\%), conventional rapeseed (20\%), conventional sunflower (5\%), conventional alfalfa (5\%) and organic wheat $(0,21 \%)$. Here on the opposite, conventional production is preferred and maize and rapeseed are at their highest level allowed, while wheat, barley and alfalfa are at their lowest.

Best results in terms of gross margin of the model farm are achieved under the Economic goal in Scenario 3: 321235900 BGN (equivalent of $241 \%$ of the target constraint), followed closely by the amount in Scenario 2 (Tab. 2, Figure 2). In terms of production structure of the farm, the best results from economic perspective include: conventional maize (37\%), organic wheat (25\%), conventional rapeseed (20\%), conventional sunflower (5\%), conventional barley $(3,96 \%)$, conventional alfalfa $(3 \%)$, organic maize $(3 \%)$, organic alfalfa (2\%) and organic barley $(1,04 \%)$. The gross margin achieved in Scenario 3 is $80 \%$ higher than the gross margin in the "No support" Scenario and this difference illustrates the contribution of the CAP incentives for the improvement of the economic results of the model farm. Furthermore, the inclusion of compensatory payments for organic farming makes some of the organically produced crops more profitable than their conventional alternatives, which has led to $30 \%$ growth in the share of organic production, compared to Scenario 2. This production structure reduced GHG emissions by $15 \%$ while increasing the corresponding gross margin by $2 \%$. The lowest gross margin of the farm is observed in the "No support" scenario under the Environmental and Optimal goals, where it does not manage to exceed the economic target constraint. However, this 
situation is overcome in the two other scenarios with the support provided by the CAP.

Effect of CAP incentives on the optimization of the model farm's economic and environmental performance

There is a beneficial effect of the CAP incentives not only on the model farm's economic per- formance but also on its environmental results. In evidence hereof, the best environmental solution in Scenario 3 results in 43\% higher gross margin than the best economic performance in Scenario 1, while cutting GHG emissions more than half. The addition of the CAP direct and compensatory payments in the model results in improvement

Table. 2. Model farm's environmental and economic performance in the different scenarios and goals

\begin{tabular}{llcccccc}
\hline \multirow{2}{*}{ Scenario } & Parameter & \multicolumn{2}{c}{ Economic goal } & \multicolumn{2}{c}{ Environmental goal } & \multicolumn{2}{c}{ Optimal goal } \\
\cline { 2 - 7 } & Result & $\begin{array}{c}\text { \% of } \\
\text { target }\end{array}$ & Result & $\begin{array}{c}\text { \% of } \\
\text { target }\end{array}$ & Result & $\begin{array}{c}\text { \% of } \\
\text { target }\end{array}$ \\
\hline \multirow{2}{*}{$\begin{array}{l}\text { 1: No } \\
\text { support }\end{array}$} & GHG, $\mathrm{CO}_{2}$-eq, kg & 751871900 & 69,33 & 245880300 & 22,67 & 299460100 & 27,61 \\
\cline { 2 - 7 } & Gross margin, BGN & 176600800 & 132,36 & 65581540 & 49,15 & 63772500 & 47,80 \\
\hline $\begin{array}{l}\text { 2: SAPS, } \\
\text { Greening }\end{array}$ & GHG, CO -eq, kg & 1266990000 & 116,82 & 245822000 & 22,67 & 249806700 & 23,03 \\
\cline { 2 - 7 } & Gross margin, BGN & 315321200 & 236,33 & 161650500 & 121,16 & 189898500 & 142,33 \\
\hline $\begin{array}{l}\text { 3: SAPS, } \\
\text { Greening, } \\
\text { OCP }\end{array}$ & GHG, CO -eq, kg & 1076455000 & 99,26 & 245822000 & 22,67 & 245822000 & 22,67 \\
\cline { 2 - 7 } & Gross margin, BGN & 321235900 & 240,76 & 253822800 & 190,24 & 253822800 & 190,24 \\
\hline
\end{tabular}

Note: The percent of target has been calculated as share of the achieved results of the target constraints $\left(1084525204 \mathrm{~kg} \mathrm{CO}_{2}\right.$-eq and 133424 160 BGN). Source: Own calculations

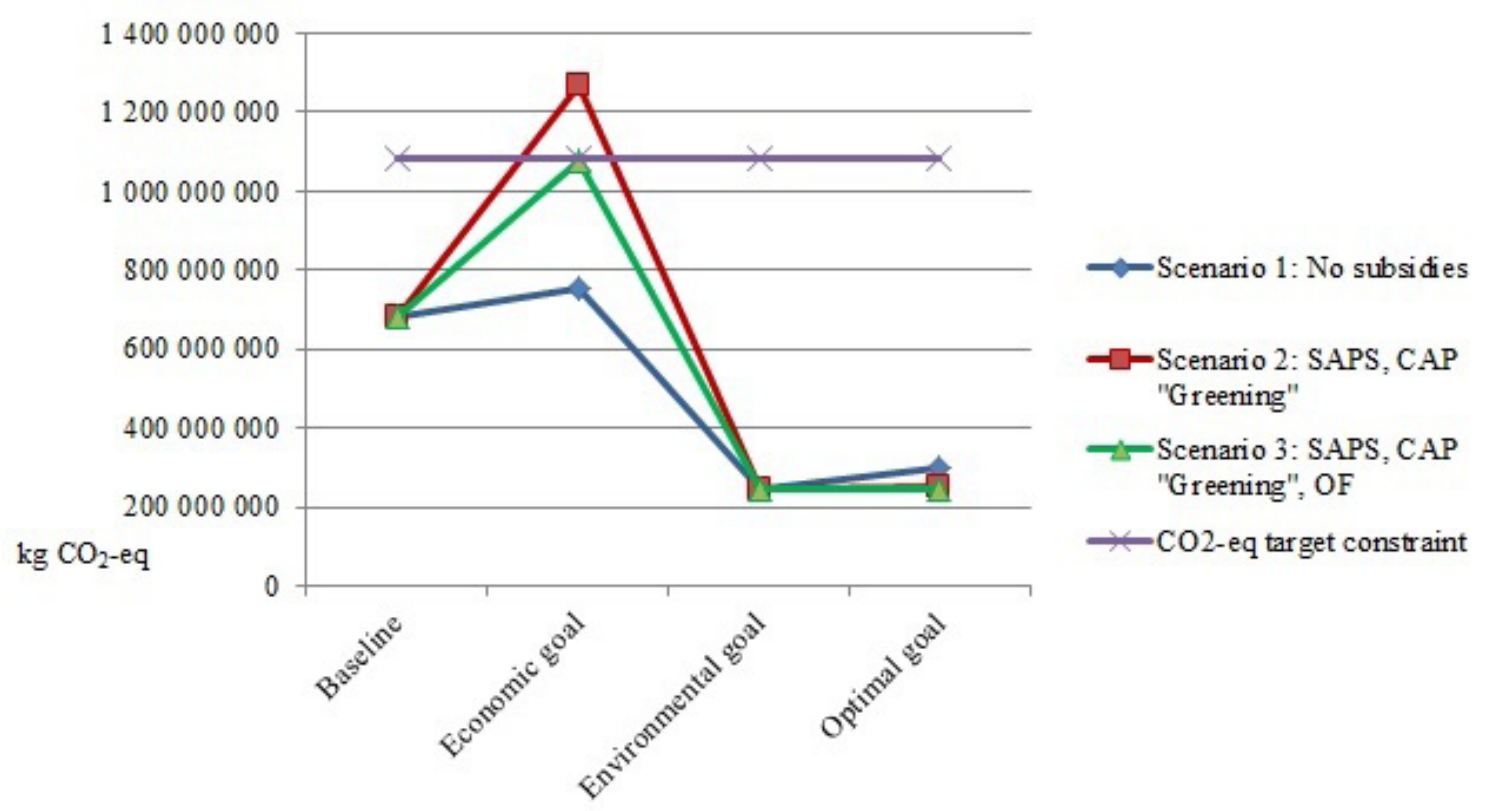

Figure 1. Carbon footprint of the farm in the different scenarios and goals, $\mathrm{kg} \mathrm{CO}_{2}$-eq. Source: Own calculations and presentation 
of the profitability of some of the crops that have better environmental performance. This reduces the large imparity between the best economic and best environmental results by bringing them closer. This can be observed by the Optimal solution results in the three scenarios: the first two optimal solutions provide transitional results - slightly higher GHG emissions and slightly lower to moderately higher gross margin, in comparison with the results under the environmental goal. In the third scenario, however, this difference has been overcome, as the optmal solution replicates the environmental solution completely. Thus, the addition of the direct and compensatory payments to the farm's gross margin, results in obtaining gross margin of 253822800 BGN at farm level (equivalent to $190 \%$ of the economic target constraint), by generating only $23 \%$ of the GHG emissions target constraint. Furthermore, the results under Scenario 3 outperform the other two scenarios under all goals (economic, environmental and optimal) by achieving higher gross margin at the same or lower GHG emission level. These results indicate that the organic farming compensatory payments build on the CAP Pillar I direct payments and improve further the farm's economic and environmental performance, achieving the best results among the modeled scenarios.

In terms of production structure, the influence of the CAP incentives is best seen in the results under the Economic and Optimal goals in the different scenarios (Tab. 3).

In the "No support" scenario's Economic goal, the production structure includes $82 \%$ conventional crops and $18 \%$ organic crops. The SAPS and Green direct payments's rates are area-based and do not differentiate conventional and organic production, which results in even higher share of conventional production in Scenario 2 (99,79\%). In terms of GHG emissions, however, this production structure generates $69 \%$ more emissions than Scenario 1 . The inclusion of the organic farming compensatory payments changes the results under the Economic goal and devotes $31 \%$ of the land to organic crops. This production structure results in 18\% lower GHG emissions than in Scenario 2, but still 43\% higher GHG emissions than in Scenario 1. The reason for the increase in the GHG emissions is the increased share of maize (from $2 \%$ conventional maize and $17 \%$ organic maize in Scenario 1 to $37 \%$ conventional maize and $3 \%$ organic maize in Scenario 3), owing to the increased profitability of this GHG-intensive crop.

\section{CONCLUSION}

The multifunctionality of agricultural land imposes making a choice between various and often mutually exclusive uses of the land. Each of these uses is characterized by differing outputs, environmental impacts and economic profit. This is why the choice between the different uses of the land requires the consideration of multiple goals and criteria. The performed optimization of the production structure of a model cereal farm showed that the availability of support is essential for the economic results of cereal farms in SouthCentral Bulgaria. Also, there is wide variation in the economic and environmental results, achieved by the model farm, under the different goals and scenarios. Generally, higher gross margin corresponds to higher emissions of greenhouse

Table. 3. Production structure of the farm in the different scenarios, share of conventional and organic production

\begin{tabular}{llccc}
\hline \multicolumn{1}{c}{ Scenario } & \multicolumn{1}{c}{ Production structure } & Economic goal & Environmental goal & Optimal goal \\
\hline \multirow{2}{*}{ 1: No subsidies } & Conventional production, $\%$ & 82,24 & 0,00 & 10,21 \\
\cline { 2 - 5 } & Organic production, $\%$ & 17,76 & 100,00 & 89,79 \\
\hline \multirow{2}{*}{ 2: SAPS, GDPS } & Conventional production, $\%$ & 99,79 & 0,01 & 40,00 \\
\cline { 2 - 5 } & Organic production, $\%$ & 0,21 & 99,99 & 60,00 \\
\hline \multirow{2}{*}{ 3: SAPS, GDPS, } & Conventional production, $\%$ & 68,96 & 0,01 & 0,01 \\
\cline { 2 - 5 } OCP & Organic production, $\%$ & 31,04 & 99,99 & 99,99 \\
\hline
\end{tabular}

Source: Own calculations 
gases and lower greenhouse gas emissions correspond to lower gross margin. Nevertheless, the addition of policy support decreases the degree of this dependency by improving the profitability of some less GHG-intensive crops. This allows cereal farmers to consider more environmentallyfriendly crops and production practices without having to cut economic profits. However, the design of the support mechanisms is very important for the achievement of the desired outcomes. The compensatory payments for organic farming under the CAP showed better results in terms of GHG emissions and gross margin of the model farm compared to the direct payments under the Single Area Payment Scheme and the Green Direct Payments. This indicates that support mechanisms designed for particular production practices show better results and are more efficient than more generally designed policy tools. In conclusion, agriculture plays an essential role for the delivery of some public goods and ecosystem services, but it can also cause severe negative impacts to the environment. In order to continue to provide these services, it is crucial for farms to achieve an optimal balance between their environmental and economic performance. The results of this model simulation showed that the created model can support farmers in these efforts, providing them with in-time information about possible decisions and related impacts. This is in line with the resultbased management concept, underlying the new CAP support mechanisms currently discussed.

Acknowledgments. This work was supported by BIOGEA project, funded through the 20152016 BiodivERsA Co-fund Call for research proposals, with the national funders Bulgarian National Science Fund, German Federal Ministry of Education and Research and National Research Agency at the Spanish Ministry of Economy and Competitiveness.

\section{REFERENCES}

1. Allen MR, Barros VR, Broome J, Cramer W, Christ R, Church JA, Clarke L, Dahe Q, Dasgupta P, Dubash NK, Edenhofer O (2014). IPCC fifth assessment synthesis report-climate change 2014 synthesis report.

2. Audsley E, Wilkinson M (2014). What is the potential for reducing national greenhouse gas emissions from crop and livestock production systems? Journal of Cleaner Production, 73: 263-268.
3. Bachev H, Ivanov B, Toteva D, Sokolova E (2017). Agricultural sustainability in Bulgaria - levels and factors. International Journal of Environmental Sciences and Natural Resources. Doi: 10.19080/ IJESNR.2017.06.555684.

4. Concepción ED, Aneva I, Jay M, Lukanov S, Marsden K, Moreno G, Oppermann R, Pardo A, Piskol S, Rolo V, Schraml A, Diaz M (2020). Optimizing biodiversity gain of European agriculture through regional targeting and adaptive management of conservation tools. Biological Conservation 241 (2020) 108384.

5. Gocht A, Ciaian P, Bielza M, Terres JM, Röder N, Himics M, Salputra G (2016). Economic and environmental impacts of CAP greening: CAPRI simulation results. Joint Research Centre, European Commission. Doi: 10.2788/452051.

6. Leip A, Carmona-Garcia G, Rossi S (2017). Mitigation measures in the Agriculture, Forestry, and Other Land Use (AFOLU) sector. Quantifying mitigation effects at the farm level and in national greenhouse gas inventories. Publication Office of the European Union, Luxembourg. Doi:10.2760/51052, JRC107178.

7. Meier MS, Stoessel F, Jungbluth N, Juraske R, Schader C, Stolze M (2015). Environmental impacts of organic and conventional agricultural products - are the differences captured by life cycle assessment? Journal of Environmental Management, 149: 193-208.

8. Ministry of Agriculture and Food (2013). Methodology and database for calculation of the compensatory payments for Measure 11 "Organic farming" (pp. 1-12). Sofia.

9. Ministry of Agriculture and Food (2016). Farm Accountancy Data Network. Results and analyses. Final results 2013. № 296-February 2016 (p.10). Sofia: Agrostatistics.

10. Ministry of Agriculture, Food and Forestry (2018). Guidance on direct payments. Campaign 2018. (pp.1-13). Sofia.

11. Ministry of Agriculture, Food and Forestry (2019). National Action Plan on Development of the Organic Farming. Sofia.National Service for Plant Protection (2008). Guidance on integrated management of pests in industrial crops (pp.3-28). Sofia: PoliTech Ltd.

12. National Statistical Institute (2018). Regions, districts and municipalities in the Republic of Bulgaria 2016, (Chapter XII Agriculture).

13. Nemecek T, Hayer F, Bonnin E, Carrouee B, Schneider A, Vivier C (2015). Designing eco-efficient crop rotations using life cycle assessment of crop combinations. European Journal of Agronomy, 65:40-51.

14. Nikolov N, Ivanov G, Stefanov L (1994). Economicmathematical modeling of agricultural production. Sofia: Zemizdat

15. Ordinance № 4 of 24.02 .2015 for the implementation of Measure 11 Organic farming under the Rural Development Programme 2014-2020, promulgated in State Gazette №16/27.02.2015.

16. Pe'er G, Lakner $S$, Müller R, Passoni G, Bontzorlos V, Clough D, Moreira F, Azam C, Berger J, Bezak P, Bonn A. Hansjürgens L, Hartmann L, Kleemann J, Lomba A, Sahrbacher A, Schindler S, Schleyer C, Schmidt J, Schüler 
S, Sirami C, von Meyer-Höfer M, Zinngrebe Y (2017) Is the CAP Fit for purpose. An evidence-based fitnesscheck assessment. Leipzig: German Centre for Integrative Biodiversity Research (iDiv) Halle-Jena-Leipzig.

17. Ordinance № RD 09-240 of 26.04.2016 of the Minister of Agriculture and Food for determining the support under the Green Direct Payments Scheme for 2015.

18. Ordinance № RD 09-341 of 03.06.2016 of the Minister of Agriculture and Food for determining the support under the Single Area Payment Scheme for Campaign 2015.

19. Shmelev SE (2012). Ecological economics: sustainability in practice. London and New York: Springer Science \& Business Media, (Chapter 5).

20. Swinton S.M, Lupi F, Robertson G.P., Hamilton S.K (2007). Ecosystem services and agriculture: cultivating agricultural ecosystems for diverse benefits. Ecological Economics, 64: 245-252.

21. Trapp M, Lakner S (2018). Fit, fair and sustainable: A model for a nature friendly and economically viable agricultural policy for Bulgaria. Study commissioned by Naturschutzbund e.V. Germany (NABU). Doi: 10.13140/ RG.2.2.15749.86240

22. Wernet G, Bauer C, Steubing B, Reinhard J, Moreno-Ruiz E, Weidema B (2017). The ecoinvent database version 3.4. https://v34.ecoquery.ecoinvent.org/Home/Index Accessed 30.01.18.

23. Zekri S, Boughanmi H (2007). Modeling the interactions between agriculture and the environment. In Handbook Of Operations Research In Natural Resources (pp. 69-91). Boston, MA: Springer. 